\title{
Comparing Lead Iodide and Lead Acetate Based Perovskite Absorber Layers by Aerosol-Assisted Chemical Vapor Deposition
}

\author{
Mohammad Afzaal, ${ }^{1}$ Shreya Basak, ${ }^{2}$ and Heather M. Yates ${ }^{3}$ \\ ${ }^{1}$ Maths and Natural Sciences Division, Higher Colleges of Technology, P.O.Box: 7947, Sharjah, United Arab \\ Emirates. Email: mafzaal@hct.ac.ae \\ ${ }^{2}$ Department of Physical Sciences, Indian Institute of Science Education and Research Kolkata, Mohanpur, 741246, \\ West Bengal, India \\ ${ }^{3}$ Materials and Physics Research Centre, University of Salford, Salford, M5 4WT, United Kingdom
}

\begin{abstract}
Aerosol-assisted chemical vapor deposition at atmospheric conditions has been used to deposit optically active lead perovskite thin films. Lead iodide and lead acetate trihydrate precursors were used and the resulting films compared. X-ray powder diffraction measurements confirmed the room temperature stable tetragonal phase which converted to monohydrate or dihydrate phase of perovskite. The stability of the differently derived films were studied by $X$-ray photoelectron spectroscopy by a detailed probing of surface chemistry and composition of deposited materials before and after argon etching.
\end{abstract}

Keywords-Absorber layers; perovskite; chemical vapor deposition; Photoluminescence

\section{INTRODUCTION}

The last few years have seen an unprecedented interest in lead-based perovskite (PK) solar cells with stable efficiencies in excess of $24 \%$ [1]. Important characteristics, for example, high absorption coefficient, superior charge transport properties, ability to tune optical bandgap and long electronhole diffusion lengths in PK layers are fundamental to improved photoconversion efficiencies in PK solar cells [2].

Before considering the technology as a serious contender to conventional silicon solar cells, low-cost processes capable of fabricating cell components on a large scale need exploring. Keeping this in mind, chemical vapor deposition (CVD) processes can be truly regarded as a commercially viable option as it is a choice of coating technology in, for example, the glass industry [3]. Many adaptations of CVD technologies are available which are helpful in circumventing issues, such as, the need for high vapor pressure precursors, deposition at reduced pressures, high operational costs and complex experiment design. Aerosol-assisted (AA) CVD process carried out at atmospheric pressure is highly attractive as long as precursor(s) are soluble in high boiling point solvents. This is necessary for generating an aerosol mist from a precursor solution, which is then transported to the heated substrate by a carrier gas. At the surface, the solvent evaporates resulting in the nucleation followed by thin film growth [4].
Several groups including ours have used AACVD to synthesize lead-based perovskite thin films. Herein, an attempt is made to systematically address the stabilities of lead iodide and lead acetate based perovskite thin films stored under different conditions. This is important from the point of view of device performance as any moisture along with air exposure has profound implications on the optical and morphological characteristics of perovskite thin films.

\section{EXPERIMENTAL WORK}

\section{Precursor Solutions}

Solutions of methylammonium lead iodide perovskite $\left(\mathrm{CH}_{3} \mathrm{NH}_{3} \mathrm{PbI}_{3}\right)$ were prepared under nitrogen $\left(\mathrm{N}_{2}\right)$ by stirring a dimethylformamide (DMF) solution of lead acetate trihydrate $\left(\mathrm{Pb}(\mathrm{Ac})_{2} \cdot 3 \mathrm{H}_{2} \mathrm{O}\right)$ or lead (II) iodide $\left(\mathrm{PbI}_{2}\right)$ with methylammonium iodide (MAI). In a typical experiment, 12 $\mathrm{mL}$ of DMF was added to $1.466 \mathrm{~g}$ of MAI in a two-neck round bottom flask. After stirring for 1 hour, $1 \mathrm{~g}$ of $\mathrm{Pb}(\mathrm{Ac})_{2} .3 \mathrm{H}_{2} \mathrm{O}$ or $1.414 \mathrm{~g}$ of $\mathrm{PbI}_{2}$ was added and stirred for 15 mins before being stored under $\mathrm{N}_{2}$. In all experiments, the molar ratio of MAI and $\mathrm{PbI}_{2}$ was fixed to $3: 1$ while that of MAI and $\mathrm{Pb}(\mathrm{Ac})_{2} \cdot 3 \mathrm{H}_{2} \mathrm{O}$ was kept at 3.5:1 to compensate for the hydrated part.

\section{A. Deposition of thin films}

Before experiment, $1.1 \mathrm{~mm}$ borosilicate glass substrates $(2.5$ $\mathrm{cm}$ in width) were cleaned with detergent, water and propan2-ol followed by air drying. The clean substrates were placed at the center (hot zone) of the AACVD chamber and heated to $140( \pm 2){ }^{\circ} \mathrm{C}$ for 30 mins to remove any native oxide from the glass surface. After placing $12 \mathrm{ml}$ of mother solution, the deposition was carried out at atmospheric pressure under a flow of nitrogen carrier gas $(0.5 \mathrm{~L} / \mathrm{min})$ for $80 \mathrm{mins}$. To prevent any oxidation of deposited films, samples were cooled at room temperature under nitrogen before removing from the chamber. For a comparative study, deposited films were stored in a nitrogen-filled glove box ( $<1 \mathrm{ppm} \mathrm{O}_{2},<2 \mathrm{ppm}$ moisture), open-air $\left(21^{\circ} \mathrm{C}\right.$ and $\left.\mathrm{RH} 75 \%\right)$ and humid chamber $\left(21^{\circ} \mathrm{C}\right.$ and RH $90 \%$ ). The relative humidity (RH) readings were carried out using a handheld thermo-hygrometer. 


\section{B. Characterization of thin films}

A Siemen D5000 instrument was used for X-ray powder diffraction (XRPD) measurements. The surface images were recorded on a Philips XL-30 FEG SEM. Photoluminescence measurements were performed with an excitation wavelength of $405 \mathrm{~nm}$ and an experimental set-up as described previously. X-ray photoelectron spectroscopy (XPS) was used to determine the surface composition of the samples using a Thermo Fisher Scientific K-alpha+ spectrometer. This used a micro-focused monochromatic $\mathrm{Al} \mathrm{X}$-ray source $(72 \mathrm{~W})$, along with a combination of low energy electrons and argon ions for charge neutralization.

\section{RESULTS AND DISCUSSION}

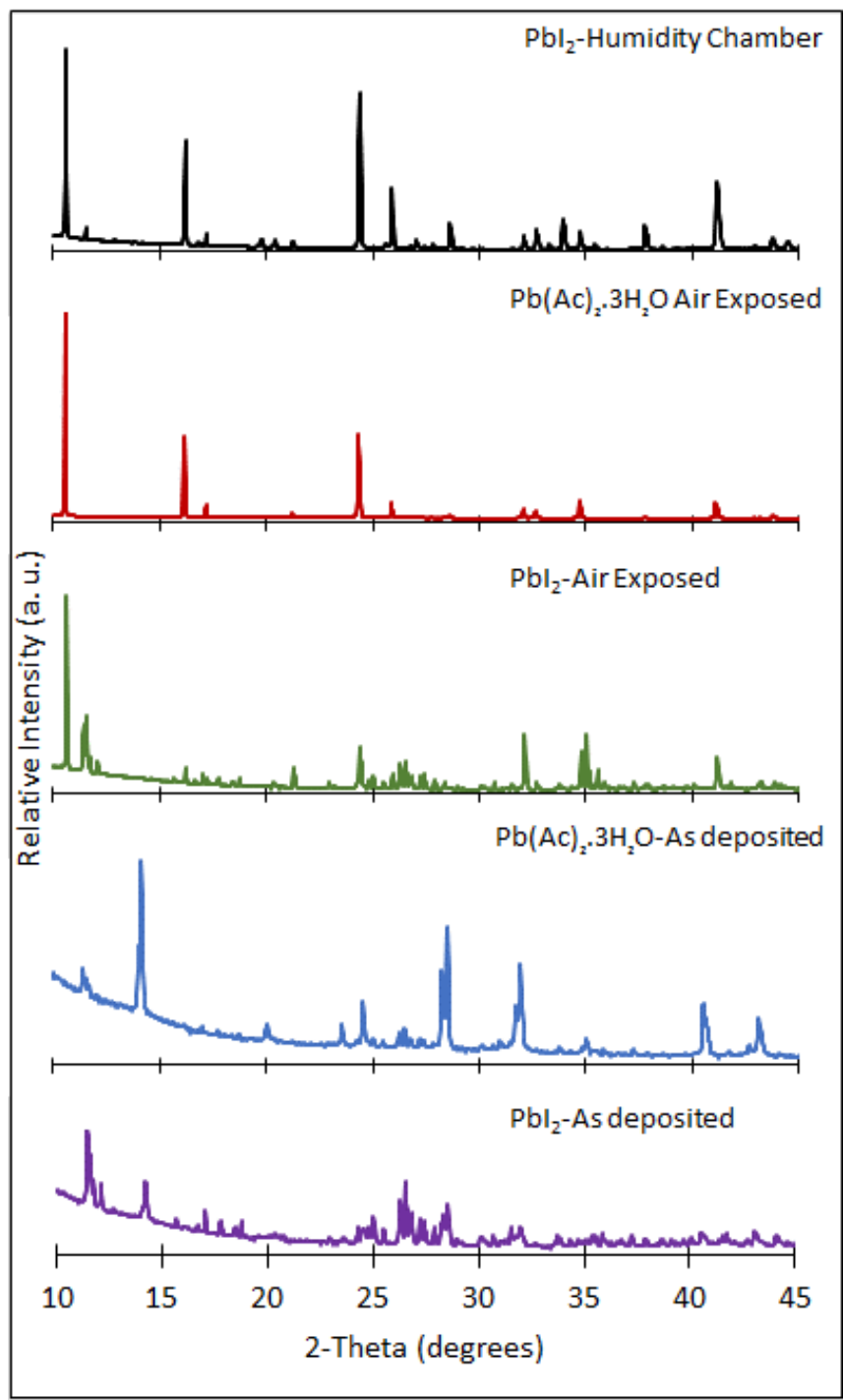

Figure 1: XRD patterns of $\mathrm{CH}_{3} \mathrm{NH}_{3} \mathrm{PbI}_{3}$ thin films stored under different conditions.
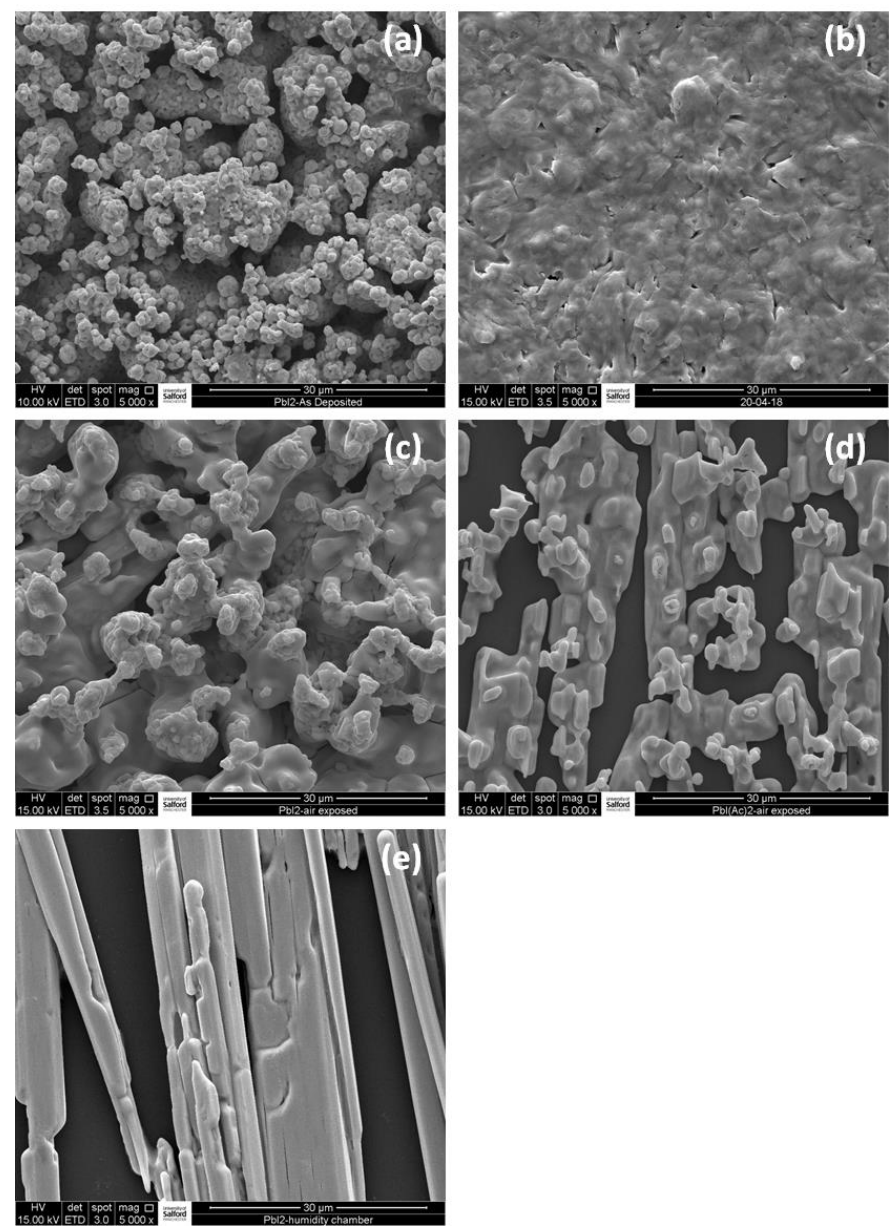

Figure 2: SEM images of $\mathrm{CH}_{3} \mathrm{NH}_{3} \mathrm{PbI}_{3}$ thin films (a) $\mathrm{PbI}_{2}$-as deposited, (b), $\mathrm{Pb}(\mathrm{Ac})_{2} \cdot 3 \mathrm{H}_{2} \mathrm{O}$-as deposited, (c) $\mathrm{PbI}_{2}$-air exposed, (d) $\mathrm{Pb}(\mathrm{Ac})_{2} .3 \mathrm{H}_{2} \mathrm{O}$-air exposed, and (e) $\mathrm{PbI}_{2}$-humidity chamber.

Lead iodide and lead acetate based perovskite absorber layers prepared by AACVD experiments were exposed to different conditions for their structural and optical sensitivities. Films are grey and could be easily scratched with a sharp object. Figure 1 shows the changes in XRD patterns as the films are exposed to different environments. Initial XRD measurements on as-deposited perovskite films, for example, show a typical room stable tetragonal phase. As the films were exposed to different humidity levels either at room temperature or in a humidity chamber, a strong peak emerged at $10.6^{\circ}$, which is characteristic of monohydrate $\left(\mathrm{CH}_{3} \mathrm{NH}_{3} \cdot \mathrm{H}_{2} \mathrm{O}\right) \mathrm{PbI}_{3}$ [8]. It is also notable that the peak at $14.16^{\circ}$, responsible for methylammonium lead iodide (MAPI), observed for asdeposited films vanished after exposure and was replaced with more intense peaks at higher $2 \theta$ values. These peaks point to the formation of polycrystalline $\left(\mathrm{CH}_{3} \mathrm{NH}_{3}\right)_{4} \mathrm{PbI}_{6} \cdot 2 \mathrm{H}_{2} \mathrm{O}$ within the perovskite films [8]. It is highly likely that the hydration of MAPI films occurs in two-steps. Initially, the crystal structure of MAPI is saturated with one water molecule per formula unit. With high humidity levels, a new structure containing two water molecules per formula is followed. A similar 
observation is report earlier where authors have studied the hydration of MAPI structures [8].

Upon air exposure, the MAPI films turned from grey/black to yellow within 24 hours. Within a humidity chamber, films became patchy and translucent pale yellow within a few hours. The SEM images given in Figure 2 show how the morphologies of MAPI change. In Figure 2a, as-deposited films from $\mathrm{PbI}_{2}$ are globular with almost full coverage. The films based on $\mathrm{Pb}(\mathrm{Ac})_{2} .3 \mathrm{H}_{2} \mathrm{O}$ are somewhat denser and closely packed with evidence of some pinholes (Figure 2b). Upon storage under at room conditions, most of the film coverage is lost as a glass substrate can be clearly seen in the images.

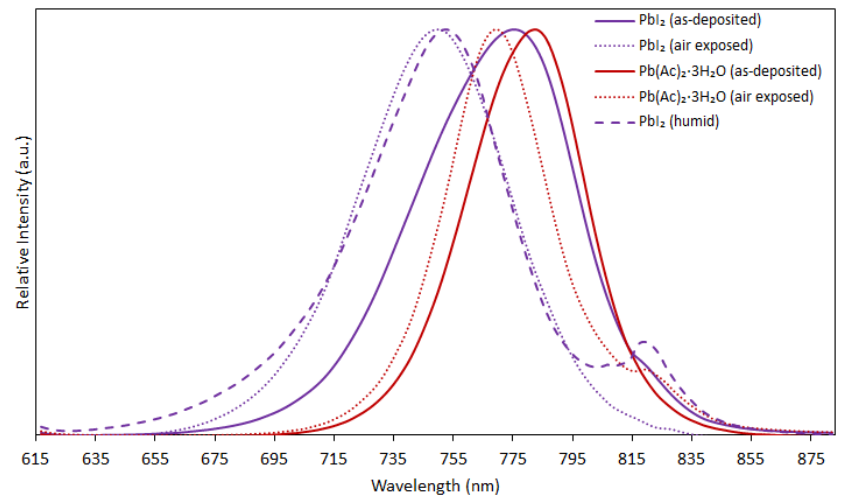

Figure 3: Photoluminescence spectra of $\mathrm{CH}_{3} \mathrm{NH}_{3} \mathrm{PbI}_{3}$ films.

Attempts to acquire reliable optical transmission and reflection data proved unfruitful, most likely a result of scattering effects from the rough surfaces. After exciting films with a blue laser (405 nm), PL response for as-deposited films was found at $\approx$ 776 and $784 \mathrm{~nm}$ for $\mathrm{PbI}_{2}$ and $\mathrm{Pb}(\mathrm{Ac})_{2} \cdot 3 \mathrm{H}_{2} \mathrm{O}$, respectively. Perhaps more importantly, PL spectra of MAPI based on $\mathrm{Pb}(\mathrm{Ac})_{2} .3 \mathrm{H}_{2} \mathrm{O}$ was much narrower $(47.97$ vs. $63.32 \mathrm{~nm})$ than that of $\mathrm{PbI}_{2}$ suggesting that the acetate related perovskite has a lower defect density. It is worth mentioning that second-order peak of the laser was removed during the handling of data. The air exposure resulted in a blue shift of 25.6 and $13.2 \mathrm{~nm}$ in perovskites formed from $\mathrm{PbI}_{2}$ and $\mathrm{Pb}(\mathrm{Ac})_{2} .3 \mathrm{H}_{2} \mathrm{O}$, respectively due to the gradual formation of $\mathrm{PbI}_{2}$. The air-exposed and humidity exposed PL peaks of films showed negligible difference in wavelength of PL maxima as well as FWHM. Considering the narrow PL responses, it can be suggested that $\mathrm{Pb}(\mathrm{Ac})_{2} .3 \mathrm{H}_{2} \mathrm{O}$ is a better precursor than $\mathrm{PbI}_{2}$ for $\mathrm{CVD}$ of perovskite thin films. The lower shift in PL overtime for the lead acetate derived perovskite suggests this may be slightly more stable.

The surface chemistry of deposited PK films was analysed by XPS. The survey scan confirmed the presence of I, N, $\mathrm{Pb}$ and $\mathrm{C}$ (Figure 4). High-resolution scans showed that the $\mathrm{C} 1 \mathrm{~s}$ consisted of two signals, The more intense signal at $286.7 \mathrm{eV}$ associated with the carbon within the methylammonium cation [9] and a smaller one due to amorphous C (285.3 eV). Although not seen on the survey scan (apart from 2 specific samples which will be discussed later), a high-resolution O1s scan showed a very weak peak. The intensity of $\mathrm{I}$ and $\mathrm{Pb}$ increased after a $10 \mathrm{~s}$ Ar etch while the $\mathrm{C}$ and $\mathrm{O}$ decreased confirming that the latter related to environmental surface contaminates. Figure 4 shows the survey scan for a representative sample both before and after the Ar etch. The concentration of oxygen related species are too low to be seen on the survey scan so the related high resolution scans for $\mathrm{O} 1 \mathrm{~s}$ are also shown.
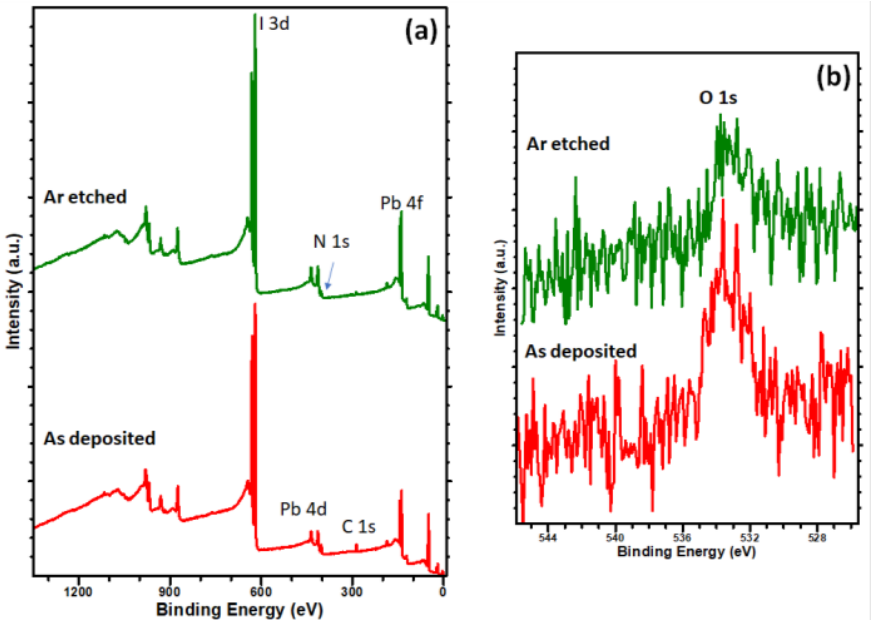

Figure 4: (a) XPS survey spectra of glovebox stored perovskite films deposited from $\mathrm{PbI}_{2}$ and high-resolution scans (b) of O1s (not seen in the survey scan).

The high resolution I 3d scan displayed only a single chemical state for the $3 \mathrm{~d}_{5 / 2}$ peak at $619.6 \mathrm{eV}$ with a characteristic splitting of $11.5 \mathrm{eV}$ [10]. The position of the $\mathrm{N} 1 \mathrm{~s}$ at $402.7 \mathrm{eV}$ is similar to that given by Zou et al. [11] and ascribed to $\mathrm{N}$ within the methylammonium ion. In all samples, the intense $\mathrm{Pb} 4 \mathrm{f}$ doublet $\left(4 \mathrm{f}_{7 / 2}\right.$ at $137.6 \mathrm{eV}$ and splitting of $4.88 \mathrm{eV}$ ) is in assigned to $\mathrm{Pb}$ within PK. Figure 5 shows high-resolution scans for both MAPI derived $\mathrm{PbI}_{2}$ and $\mathrm{Pb}(\mathrm{Ac})_{2} \cdot 3 \mathrm{H}_{2} \mathrm{O}$. A few samples establish the presence of a lower intensity signal with $4 f_{7 / 2}$ at 137.1 $\mathrm{eV}$ related to metallic $\mathrm{Pb}$. This is especially noticeable after the Ar etch. Metallic $\mathrm{Pb}$ within perovskite samples has been previously reported and has been attributed to decomposition during annealing [12], laser irradiation [13] or beam damage during measurements [10].

As the intensity of the peak noticeably increased after Ar etching the majority of the $\mathrm{Pb}$ presence is ascribed to beam damage. This was especially obvious in the lead Acetate derived samples where the $\mathrm{Pb}^{0}$ content approximately doubled on etching with, for example, rising from $6 \%$ to $13 \%$ of the total $\mathrm{Pb}^{0}$ content in the samples stored within a dry glove box. See figure 5 for a comparison of the effect of etching on the differently derived MAPI samples. At the same time, this is mirrored with a reduction in the relative amount of $\mathrm{N}$, which may indicate some PK decomposition. However, there is no obvious change in the very small high-resolution $\mathrm{O} 1 \mathrm{~s}$ 
signal, so establishing that no significant absorption of moisture took place, unlike that reported by Wang and coworkers [9].

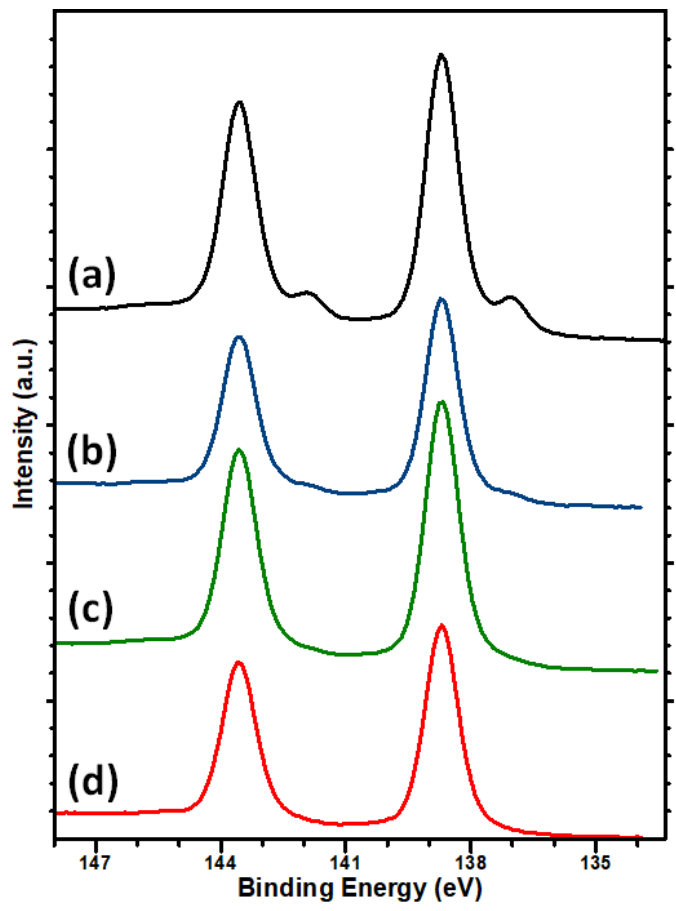

Figure 5: High-resolution XPS scans of $\mathrm{Pb} 4 \mathrm{f}$. (a) After argon etch and (b) as-deposited from $\mathrm{Pb}(\mathrm{Ac})_{2} \cdot 3 \mathrm{H}_{2} \mathrm{O}$. (c) After argon etch (d) as-deposited from $\mathrm{PbI}_{2}$.

A range of PK samples were analyzed (Figure 6) and the effects of initial precursor and storage conditions considered. Prior to calculation of PK stoichiometry, both the metallic $\mathrm{Pb}$ and amorphous $\mathrm{C}$ components were removed. Table 1 shows that the ratio of $\mathrm{Pb}: \mathrm{I}: \mathrm{N}: \mathrm{C}$ is not that of a perfect PK samples (1:3:1:1). In particularly the $\mathrm{N}$ and especially $\mathrm{C}$ values obtained are not accurate due to interference from the $\mathrm{Pb} 4 \mathrm{~d}_{5 / 2}$ signal for $\mathrm{N} 1 \mathrm{~s}$, the low intensity of the peaks and poor signal/noise level for particularly the $\mathrm{C} 1 \mathrm{~s}$. Many papers report almost perfect stoichiometry for the perovskite as derived from XPS measurements. However, most of these have deposited the PK films in a vacuum with direct transfer to the
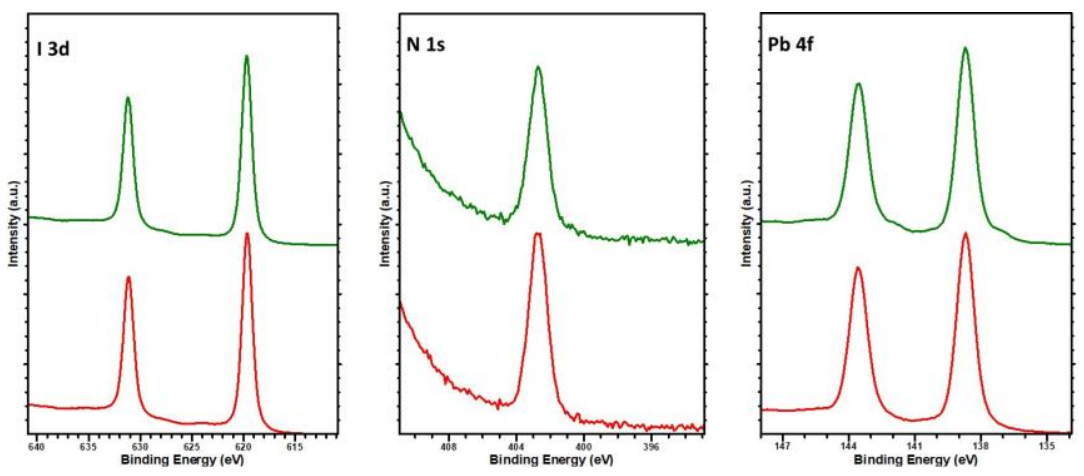

Figure 6. High-resolution scans of as-deposited film constituents resulting from $\mathrm{Pb}(\mathrm{Ac})_{2} .3 \mathrm{H}_{2} \mathrm{O}$ (top) and $\mathrm{PbI}_{2}$ (bottom).
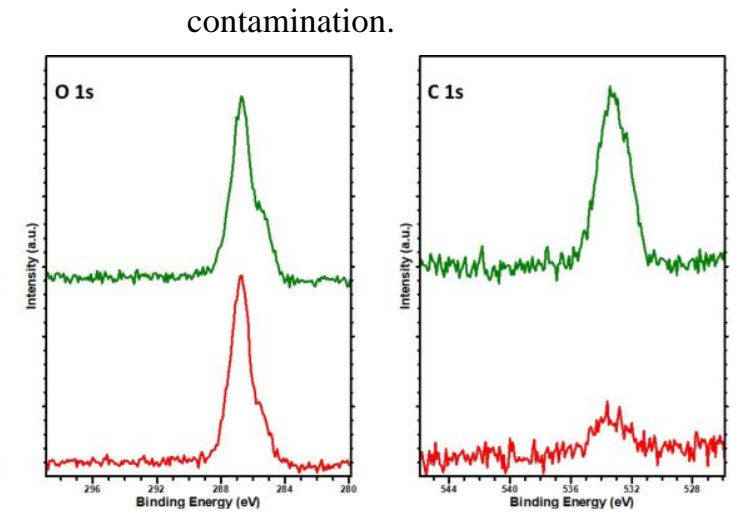

XPS instrument [9, 11, 13], controlled low humidity $(<30 \%)$ [14]. Our samples were prepared in an with limited control over the timescale between deposition and analysis. The latter was minimised by transporting the samples in sealed, evacuated bags. However, as all samples were treated similarly conclusions can still be reached from relative comparisons between the differently treated samples.

As the Ar etch led to damage of the films, the discussion will concentrate on the initial surface scan as more representative of the samples. Use of lead acetate rather than lead iodide lead to samples with similar stoichiometry, close to that of the perovskite. These samples stored in a glove box (with controlled low humidity and low light levels) showed limited decomposition. In comparison, the samples stored in the open reduction in the amount of $\mathrm{I}$ to $\mathrm{Pb}$ due to the start of decomposition to $\mathrm{PbI}_{2}$ and the discharge of the $\mathrm{HI}$ and $\mathrm{NH}_{3}$ into the air [9]. The amount of decomposition is still low, as no sign of any yellow $\mathrm{PbI}_{2}$ and the samples retain their black coloration.

\begin{tabular}{|c|c|c|c|c|c|c|}
\hline Precursor & Sample & Storage & $\mathrm{Pb}$ & I & $\mathrm{N}$ & $\mathrm{C}$ \\
\hline \multirow{6}{*}{$\begin{array}{l}\text { Lead } \\
\text { iodide }\end{array}$} & \multirow[t]{2}{*}{ S4 } & Glove box & 1 & 2.7 & 0.8 & 1.0 \\
\hline & & Ar etch & 1 & 2.0 & 0.4 & 0.5 \\
\hline & \multirow[t]{2}{*}{ S5 } & $\begin{array}{c}\text { As- } \\
\text { deposited, } \\
\text { open lab }\end{array}$ & 1 & 2.6 & 0.9 & 1.6 \\
\hline & & Ar etch & 1 & 2.0 & 0.4 & 0.7 \\
\hline & \multirow[t]{2}{*}{ S6 } & $\begin{array}{l}\text { Humidity } \\
\text { chamber }\end{array}$ & 1 & 2.5 & 0.9 & 1.9 \\
\hline & & Ar etch & 1 & 2.0 & 0.3 & 0.5 \\
\hline \multirow{4}{*}{$\begin{array}{c}\text { Lead } \\
\text { acetate } \\
\text { trihydrate }\end{array}$} & \multirow[t]{2}{*}{ S7 } & Glove box & 1 & 2.7 & 0.8 & $1.0 *$ \\
\hline & & Ar etch & 1 & 2.0 & 0.3 & 0.4 \\
\hline & \multirow[t]{2}{*}{ S8 } & $\begin{array}{c}\text { As- } \\
\text { deposited, } \\
\text { open lab }\end{array}$ & 1 & 2.4 & 0.9 & $1.9^{*}$ \\
\hline & & Ar etch & 1 & 1.9 & 0.2 & 0.4 \\
\hline
\end{tabular}

Table 1. XPS analysis of perovskite thin films. *Third small peak at $288.7 \mathrm{eV}$, removed on etching, so probably surface contamination lab environment with high humidity and room light showed a 




Figure 7. High-resolution spectra $\mathrm{O}$ 1s. (a) $\mathrm{Pb}(\mathrm{Ac})_{2} \cdot 3 \mathrm{H}_{2} \mathrm{O}$ stored in open lab, (b) $\mathrm{PbI}_{2}$ in humidity chamber, (c) $\mathrm{Pb}(\mathrm{Ac})_{2} \cdot 3 \mathrm{H}_{2} \mathrm{O}$ in glovebox, (d) $\mathrm{PbI}_{2}$ in open lab, and (e) $\mathrm{PbI}_{2}$ in glovebox.

Interestingly the relative amount of $\mathrm{Pb}^{0}$ (to total $\mathrm{Pb}$ ) does not change for either sample (S4 and S7) on exposure to the open lab, although the lead acetate derived sample contains a greater proportion $(8.5 \%$ over $4.1 \%)$. However, the stability of the lead acetate derived films seems to be less as judged by greater reduction of $\mathrm{Pb}: \mathrm{I}$.

Only two samples, PK exposed in a humidity chamber $(80 \%$ humidity), S6, and the lead acetate derived sample after being left in an open lab, S8 showed a well resolved, although low intensity $\mathrm{O} 1 \mathrm{~s}$ (Figure 7). This peak at $533.4 \mathrm{eV}$ is usually ascribed to oxygen within silica. This is confirmed by a weak Si $2 \mathrm{p}$ peak at $103.8 \mathrm{eV}$. This suggests that in these samples there are pin-holes in the analyzed film giving access to the $\mathrm{SiO}_{2}$ glass substrate. SEM image (Figure 2e) confirms the major structural changes for particularly the humidity chamber treated sample, S6. Additional proof of the major changes the humidity treated sample also shows an increase from $4.1 \%$ to $10.2 \%$ of the relative metallic $\mathrm{Pb}$ content.

\section{CONCLUSIONS}

A single-step AACVD process has been utilized to deposit $\mathrm{CH}_{3} \mathrm{NH}_{3} \mathrm{PbI}_{3}$ thin films using two different lead precursors and properties compared. Detailed analysis showed that the resulting characteristics of deposited films depend both on the initial lead precursor and how the films are stored. Photoluminescence data exhibited much narrow emission peaks for $\mathrm{Pb}(\mathrm{Ac})_{2} .3 \mathrm{H}_{2} \mathrm{O}$ rather than $\mathrm{PbI}_{2}$ derived films. A thorough surface analysis demonstrated different stoichiometries, stability, morphology and level of especially carbon contaminants.

\section{ACKNOWLEDGEMENTS}

This work has received funding from the European Union's Horizon 2020 research and innovation programme under grant agreement No. 653296 (CHEOPS). XPS data collection was performed at the EPSRC National Facility for XPS ('HarwellXPS'), operated by Cardiff University and UCL, under contract No. PR16195. SB would like to thank KVPYDST for the fellowship. Dr J. E. Proctor and H. Malik (University of Salford) are acknowledged for assistance with the photoluminescence measurements.

\section{REFERENCES}

[1] A. Agresti, A. Pazniak, S. Pescetelli, A. Di Vito, D. Rossi, A. Pecchia, M. Auf der Maur, A. Liedl, R. Larciprete, Denis V. Kuznetsov, D. Saranin, and A. Di Carlo, Titanium-Carbide MXenes for Work Function and Interface Engineering in Perovskite Solar Cells, Nature Materials, vol. 18, pp. 1228-1234, 2019.

[2] (a) S. D. Stranks, G. E. Eperon, G. Grancini, C. Menelaou, M. J. Alcocer, T. Leijtens, L. M. Herz, A. Petrozza, and H. J. Snaith, "Electron-hole diffusion lengths exceeding 1 micrometer in an organometal trihalide perovskite absorber", Science, vol. 342, pp. 341 344, 2013; (b) J.-M. Yang, Y. Luo, Q. Bao, Y.-Q. Li and J.-X. Tang, "Recent advances in energetics and stability of metal halide perovskites for optoelectronic applications," Advanced Materials Interfaces, vol. 6, pp. 1801351, 2019.

[3] M. Afzaal, H. M Yates, A. Walter, and S. Nicolay, "Improved FTO/NiOx interfaces for inverted planar triple-cation perovskite solar cells” IEEE Journal of Photovoltaics, vol. 9, pp. 1302-1308, 2019.

[4] M. J. Powell, D. B. Potter, R. L. Wilson, J. A. Darr, I. P. Parkin, and C. J. Carmalt, "Scaling aerosol assisted chemical vapour deposition: Exploring the relationship between growth rate and film properties". Materials \& Design, vol. 129, pp. 116-124, 2017.

[5] S. Chen, J. Briscoe, Y. Shi, K. Chen, R. M. Wilson, S. Dunn and R Binions, "A simple, low-cost CVD route to high-quality $\mathrm{CH}_{3} \mathrm{NH}_{3} \mathrm{PbI}_{3}$ perovskite thin films", CrystEngComm, vol, 17, pp, 74867489, 2015 .

[6] D. J. Lewis and P. O'Brien, “Ambient pressure aerosol-assisted chemical vapour deposition of $\left(\mathrm{CH}_{3} \mathrm{NH}_{3}\right) \mathrm{PbBr}_{3}$, an inorganic-organic perovskite important in photovoltaics", Chemical Communications, vol. 50, pp. 6319-6321, 2014.

[7] M. Afzaal, and H. M. Yates, "Growth patterns and properties of aerosolassisted chemical vapor deposition of $\mathrm{CH}_{3} \mathrm{NH}_{3} \mathrm{PbI}_{3}$ films in a single step", Surface and Coatings Technology, vol. 321, pp. 336-340, 2017.

[8] A. M. A. Leguy, Y. Hu, M. Campoy-Quiles, M. I. Alonso, O. J. Weber, P. Azarhoosh, M. van Schilfgaarde, M. T. Weller, T. Bein, J. Nelson, P. Docampo, and P. R. F. Barnes, "Reversible hydration of $\mathrm{CH}_{3} \mathrm{NH}_{3} \mathrm{PbI}_{3}$ in films, single crystals, and solar cells", vol. 27, pp. 3397-3407, 2015.

[9] C. Wang, Y. Li, X. Xu, C. Wang, F. Xie and Y. Gao, "Degradation of co-evaporated perovskite thin film in air", Chemical Physics Letters, volume 649, pp. 151-155, 2016.

[10] S. R. Raga, M.-C. Jung, M. V. Lee, M. R. Leyden, Y. Kato, and Y. Qi, "Influence of air Annealing on high efficiency planar structure perovskite solar cells“, Chemistry of Materials, vol. 27, pp. 1597-1603, 2015.

[11] Y. Zou, Q. Meng, H. Mao and D. Zhu, "Substrate effect on the interfacial electronic structure of thermally-evaporated $\mathrm{CH}_{3} \mathrm{NH}_{3} \mathrm{PbI}_{3}$ perovskite layer", Organic Electronics, vol. 41, pp. $307-$ 314, 2017.

[12] H, Xie, X, Liu, L. Lyu, D. Niu, Q. Wang, J. Huang, and Y. Gao, "Effects of Precursor Ratios and Annealing on Electronic Structure and Surface 
Composition of $\mathrm{CH}_{3} \mathrm{NH}_{3} \mathrm{PbI}_{3}$ Perovskite Films", Journal of Physical Chemistry C vol. 120, pp. 215-220, 2016.

[13] Y. Li, X. Xu, C. Wang, B. Ecker, J. Yang, J. Huang, and Y. Gao, "Lightinduced degradation of $\mathrm{CH}_{3} \mathrm{NH}_{3} \mathrm{PbI}_{3}$ hybrid perovskite thin film", Journal of Physical Chemistry C vol. 121, pp. 3904-3910, 2017.

[14] R. Lindblad, D. Bi, B.-W. Park, J. Oscarsson, M. Gorgoi, H. Siegbahn, M. Odelius, E. M. J. Johansson, and H. Rensmo, Electronic structure of $\mathrm{TiO}_{2} / \mathrm{CH}_{3} \mathrm{NH}_{3} \mathrm{PbI}_{3}$ perovskite solar cell interfaces", The Journal of Physical Chemistry letters, vol, 5, pp. 648-653, 2014. 